\title{
Oral calcium suppresses increased rectal epithelial proliferation of persons at risk of colorectal cancer
}

\author{
P ROZEN, Z FIREMAN, N FINE, Y WAX, AND E RON
}

From the Departments of Gastroenterology, Tel-Aviv Medical Center and Clinical Epidemiology, Chaim Sheba Medical Center, Sackler Medical Faculty, Tel-Aviv University, Israel, Biometry Branch, DCPC and Radiation Epidemiology Branch, DCE National Cancer Institute NIH, Bethesda, Md, USA

SUMmaRY Dietary calcium may inhibit colonic carcinogenesis promoted by high fat, phosphate, and low fibre diets. In persons at risk for colon cancer oral calcium supplements significantly suppress increased rectal epithelial proliferation. This was studied in a cohort of 35 volunteers: 26 first degree relatives of colorectal cancer patients and nine who had had colonic adenomas (mean age $51 \cdot 6$ years, 17 (49\%) men, all negative for large bowel neoplasia). 1.25-1.5 g elemental calcium was given in divided daily doses for three months. Rectal pinch biopsies were taken without bowel preparation, before and mean 8.4 weeks during and $7 \cdot 2$ weeks after treatment and incubated with tritiated thymidine. The mean number of labelled cells, as a ratio of the total number of crypt cells (labelling index - LI), and their crypt position, were determined. The mean number of labelled cells decreased during treatment by $29 \%$, especially in the basal three-fifths of crypts. There was also a significant $10 \%$ increase in mean number of crypt cells during treatment. [Mean LI decreased by $36 \%(p<0.001)$ during calcium treatment and almost returned to basal values after cessation.] If a raised $\mathrm{LI}$ is a marker of potential malignancy and a randomised clinical trial confirms that calcium suppresses it, dietary intervention studies in high risk persons are indicated.

As colorectal cancer is one of the most common internal malignancies of the Western world, its prevention is of prime importance. Environmental and dietary factors are believed to be paramount in the aetiology of the majority of cases $(85-90 \%)$ while the remainder are genetic-familial. ${ }^{12}$

While total caloric intake and the balance between the macronutrients fat and fibre, are believed to be of prime importance in the aetiology of large bowel malignancies, the epidemiological evidence is not consistent ${ }^{13}$ and for these reasons, the role of micronutrients has been investigated. In 1984, it was suggested that a lack of dietary calcium, in the presence of a high fat and phosphate, low fibre diet, causes an increased level of free ionized fatty and bile acids to appear within the colonic luminal contents. ${ }^{4}$ These acids can damage the colonic mucosa, increase epithelial cell proliferation and possibly act as pro-

Address for correspondence: Prof P Rozen, Dept of Gastroenterology, Ichilov Hospital, 6 Weizman Street, Tel-Aviv 64239, Israel.

Accepted for publication 3 October 1988. moters of colonic carcinogenesis. Also local toxic effects of fat and bile might be inhibited by the presence of ionized calcium, which could form insoluble soaps and our Western diet could contain insufficient calcium. ${ }^{+7}$ Evidence supporting these hypotheses comes from epidemiological correlation studies. ${ }^{84}$

An abnormally increased proliferation of colonic epithelial cells has been shown in subjects who have had large bowel neoplasia ${ }^{11}$ and in their asymptomatic relatives. ${ }^{11}$ Thus, they would seem to be ideal subjects for intervention studies using their crypt proliferation pattern as an objective marker of response. This supposition was tested by Lipkin and Newmark ${ }^{12}$ in a small group of asymptomatic persons who belonged to families at high risk for colon cancer. They were given calcium carbonate by mouth for three months and a significant suppression of their colonic epithelial proliferation was demonstrated. Our larger study extends and confirms these findings and, in addition, attempts to evaluate time of onset of 650 
effect, type of calcium salt used and host factors which might modify response to calcium supplementation. ${ }^{13}$

\section{Methods}

POPULATION

A group of asymptomatic first degree relatives of colorectal cancer patients or patients with previous large bowel adenoma, were invited to volunteer for the study as it was thought they may have an increased risk for colorectal cancer. These subjects, aged 40 to 70 years, are being followed in our Colorectal Cancer Screening Clinic and have all screened negative for faecal occult blood and for neoplasia by flexible sigmoidoscopy (for the relatives) or colonoscopy (past history of neoplasia) ${ }^{14}$ Excluded were those having a duodenal ulcer, nephrolithiasis, renal insufficiency or hypercalcaemia. A dietary history was obtained by a specially trained dietician and the results will be presented elsewhere. The volunteers were requested not to change their dietary habits during the course of the trial.

CALCIUM TREATMENT

$1 \cdot 25-1.5 \mathrm{~g}$ of elemental calcium was given daily for three months either in the form of calcium carbonate powder (BP) $3.75 \mathrm{~g} /$ day or tablets of an effervecent calcium gluconate-lactate-carbonate preparation (Calcium Forte ${ }^{\mathrm{Tm}}$ Sandoz, Basel) providing a similar amount of elemental calcium. The tablets were taken as a drink three times a day, while the powder was sprinkled twice a day, from a preweighed measure, on to milk or milk products.

Before starting and then monthly during treatment, a urine examination was carried out and blood calcium, urea and creatinine values were determined. Compliance was assessed indirectly by examining monthly the returned medication containers and by the fact that the volunteers completed the monthly laboratory tests and submitted to repeated rectal biopsy examinations during and after the study.

\section{BIOPSIES}

One or two biopsies were taken between 8-10 am without bowel preparation, using fibreoptic pinch biopsy forceps. ${ }^{15}$ While guiding the flexible forceps with the index finger, samples were obtained, 8-10 $\mathrm{cm}$ from the anal verge, from the posterior wall of the rectum. Samples were taken before calcium therapy, again at four to six and, or eight to 12 weeks during treatment and again six to eight weeks after stopping treatment.

The biopsies were coded and oriented mucosal side up, on filter paper, with the aid of a dissecting microscope. They were immediately placed in a Petri dish containing $3 \mathrm{ml}$ Eagle's medium and tritiated thymidine, $5 \mu \mathrm{Ci} / \mathrm{ml}$ (Nuclear Research Center, The Negev). The biopsies were then incubated at $37^{\circ} \mathrm{C}$ in a rocking chamber with $95 \% \mathrm{O}_{2}$ and $5 \% \mathrm{CO}_{2}$ for 90 minutes, then washed with buffered phosphate and placed in $10 \%$ neutral buffered formalin. Batches of biopsies were oriented mucosal side up in paraffin blocks, sectioned and slides prepared. These were dipped in Kodak developing emulsion $\mathrm{NBT}_{2}$ for several minutes and placed in a light tight box at $4^{\circ} \mathrm{C}$ for three weeks. The slides were then dipped in Kodak-19 solution at $18^{\circ} \mathrm{C}$ to stop further development, then in Kodak fixative F-10, washed and stained with haematoxylin and eosin.

READING OF SLIDES

Five coded slides were prepared from each biopsy and 15 to 25 well oriented crypts counted, taking care not to recount the same crypt. Each side of the crypt ('column') was counted from the base (extending from the muscularis mucosa) to the surface epithelium, noting the number of cells, the number of labelled (four or more silver grains) nuclei and their position in the crypt column (Fig. 1). Each coded biopsy was read, at random, by the same technician.

\section{ANALYSIS}

The program coordinator added the personal data to each work sheet and grouped them by identification number. She excluded from the analysis those persons who did not complete the trial or did not have technically satisfactory biopsies before and at least once during therapy. The work sheets were then transfered to the collaborating institution for data entry and computer analysis using self-developed programs based on experience described elsewhere. ${ }^{12}$

Three parameters were used to assess the treatment effect: the mean number of cells per crypt column; the mean number of labelled cells per column; and a 'Labelling Index' (LI), which is the ratio of labelled to the total number of crypt cells. In addition, the crypt column was divided into five compartments (from base to surface) and the number of cells and labelled cells in each compartment were calculated. This provided a LI for each of the five compartments (Fig. 1).

Analysis was based on the individual and mean values of the study parameters at the start, during, and after treatment. Although no comparable nontreated control group was studied, the short turnover time of colonic epithelial cells (few days) suggests that the after treatment level provides a 'proxy' intra-subject control.

The values of the parameters during treatment 


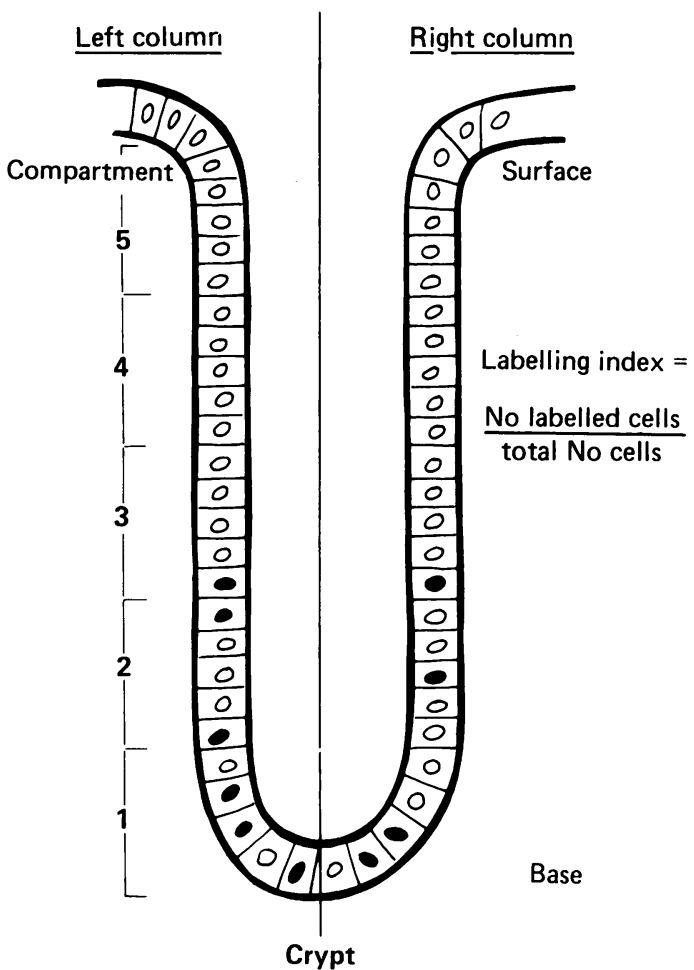

Fig. 1 Schematic figure demonstrating how a well oriented crypt is divided into two 'columns' and each column into five equal 'compartments' according to the number of cells in each column. Nuclei, capable of undergoing division, take up tritiated thymidine and appear to have dark granules after autoradiography. These and the total number of nuclei lining each crypt are counted and their ratio provides the labelling index $-L I$.

were compared with both baseline and after treatment values using paired $t$ tests. The effect of an individual's baseline value on treatment response was assessed by analysing the data separately for subjects having above and below the mean baseline value. The possible modifying effect of sex, age, reason to enter into the trial (family or past history of colorectal neoplasia) and type of calcium preparation used, were also examined.

The study was approved by the hospital Ethics (Helsinki) Committee in 1985 and all participants gave their informed, written consent.

\section{Results}

Fifty persons volunteered for the study. Three withdrew because of intolerance of the calcium preparations; one had upper gastrointestinal complaints from the calcium carbonate, another from calcium gluconate-lactate and the third complained of pruritus
Table 1 Characteristics of volunteers having rectal epithelial proliferation studies and taking calcium*

\begin{tabular}{llc}
\hline & \multicolumn{2}{c}{$\begin{array}{c}\text { Family history or Past history } \\
\text { of colorectal neoplasia }\end{array}$} \\
\hline $\mathrm{n}$ & $26^{\dagger}$ & $9 \ddagger$ \\
Men & 12 & 5 \\
Age (mean (SD) & $50 \cdot 0(8 \cdot 5) \S$ & $56 \cdot 6(5 \cdot 3) \S$ \\
Calcium carbonate & 17 & 9 \\
Calcium gluconate-lactate & 9 & 0 \\
\hline
\end{tabular}

$*_{1} \cdot 25-1.5 \mathrm{~g}$ elemental calcium/day for three months: $†$ All had one first degree relative with colorectal cancer and seven had two or more relatives. None had adenomas; $\ddagger$ All had significant sized $(>0.5$ $\mathrm{cm}$ ) adenomas in the past and five had first degree relatives with colorectal cancer; $\$$ The ages are significantly different.

Table 2 Rectal epithelial proliferation studies before, during and after calcium treatment

\begin{tabular}{|c|c|c|c|}
\hline & Before & $\begin{array}{l}\text { During } \\
\text { treatment }\end{array}$ & After \\
\hline $\mathrm{n}$ & 35 & 35 & 31 \\
\hline Weeks (mean) & - & $8 \cdot 4$ & $7 \cdot 2$ \\
\hline $\begin{array}{l}\text { Crypts counted (n) (mean } \\
\text { (SD)) }\end{array}$ & $15 \cdot 6(4 \cdot 8)$ & $15 \cdot 5(3 \cdot 9)$ & $18 \cdot()(5 \cdot 7)$ \\
\hline $\begin{array}{l}\text { Cells/crypt column }(\mathrm{n})^{*} \\
(\text { mean }(\mathrm{SD}))\end{array}$ & $41 \cdot 5(3 \cdot 9)$ & $45 \cdot 6(4 \cdot 4) \dagger$ & $44 \cdot 7(5 \cdot 4)^{\dagger}$ \\
\hline $\begin{array}{l}\text { Labelled cells/crypt column } \\
\qquad(\mathrm{n})^{*}(\text { mean }(\mathrm{SD}))\end{array}$ & $\begin{array}{l}2 \cdot 17 \\
(0 \cdot 88)\end{array}$ & $\begin{array}{l}1.54 \\
(0 \cdot 58) \dagger\end{array}$ & $2 \cdot(19)(1 \cdot(04)$ \\
\hline
\end{tabular}

*Two columns/crypt; $†$ These results are significantly $(\mathrm{p}<0 \cdot() 1)$ different from basel values.

from calcium carbonate. A laboratory mishap resulted in the loss of a batch of autoradiography specimens which precluded sequential analysis of a further 12 cases. Thus, 35 completed the study and their characteristics are given in Table 1 . Those with a past history of colorectal neoplasia were significantly older than the volunteers with a family history of large bowel cancer. Subgroup analyses indicated no difference in results by risk group; sex; age, or calcium preparation used. Therefore, results are presented only for the total study population.

Table 2 shows the mean measurements of epithelial proliferation before, during, and after calcium therapy. Although there was a significant $(p<0.01)$ increase in the number of crypt cells (depth) both during and after calcium treatment, the number of thymidine labelled cells was significantly reduced $(p<0.01)$ only during treatment, compared with both base line and after treatment values. Thus, the LI decreased significantly $(p<0.01)$ only during calcium therapy and this was most prominent $(p<0.01)$ in the basal three-fifths of the crypts (Table 3).

Further analysis showed that, of the 35 persons in the study group, 14 members, nine men and five 
Table 3 Changes in overall labelling index (LI) and in crypt compartments' $L I$ during and after calcium treatment

\begin{tabular}{lllll}
\hline & \multicolumn{3}{l}{$\begin{array}{l}\text { During } \\
\text { treatment }\end{array}$ After } \\
\hline $\begin{array}{l}\text { Labelling index } \times 100 \text { (mean } \\
\text { (SD)) }\end{array}$ & $5 \cdot 3(2 \cdot 2)$ & $3 \cdot 4(1 \cdot 3)^{*}$ & $4 \cdot 7(2 \cdot 3)$ \\
LI/compatment $\times 100$ (mean & 1 & $6 \cdot 6(4 \cdot 3)$ & $4 \cdot 4(2 \cdot 5)^{*}$ & $6 \cdot 3(3 \cdot 5)$ \\
(SD)) & 2 & $9 \cdot 7(5 \cdot 3)$ & $6 \cdot 0(3 \cdot 3)^{*}$ & $8 \cdot 5(4 \cdot 1)$ \\
& 3 & $7 \cdot 1(2 \cdot 8)$ & $4 \cdot 3(2 \cdot 6)^{*}$ & $5 \cdot 6(3 \cdot 5)$ \\
& 4 & $2 \cdot 5(1 \cdot 8)$ & $2 \cdot 1(2 \cdot 0)$ & $2 \cdot 3(2 \cdot 1)$ \\
& 5 & $0 \cdot 4(0 \cdot 6)$ & $0 \cdot 8(2 \cdot 2)$ & $0 \cdot 3(0 \cdot 7)$ \\
\hline
\end{tabular}

*These results are significantly $(\mathrm{p}<0 \cdot 01)$ different from basal values.

women, mean age 49.8 years $(2 \cdot 4)$ (SD), had basal LI values greater than the mean for the entire group. Their mean LI $(\times 100)$ fell by $58 \%$, from 7.5 to 3.3 during calcium treatment. As noted, response was independent of risk group, calcium preparation used, sex or age. While seven of the remaining 21 volunteers, who had basal LI values less than the mean, had a slight insignificant rise in their LI measurements during therapy. Thus, as a group, the fall of $35.9 \%$ in LI values during calcium intake was the result of the suppression of thymidine uptake in those individuals having an initially raised LI.

In order to estimate when the response to calcium occurred, measurements of epithelial proliferation during treatment were measured. Basal and repeated biopsy readings after four to six weeks and eight to 12 weeks' treatment were available for 17 and 30 subjects, respectively. The baseline values of the 17 subjects having the early repeated biopsies, were not different from the rest of the study population. As

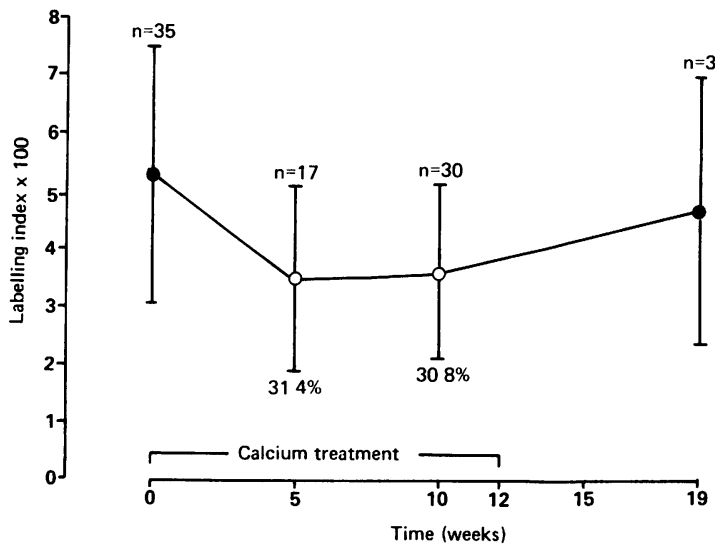

Fig. 2 A significant $(\diamond)(p<0.001)$ fall in LI (mean $(S D)$ at five and 10 weeks, of $31.4 \%$ and $30 \cdot 8 \%$ respectively (comparing each to their own basal values), during calcium treatment and its reversal after cessation of treatment.

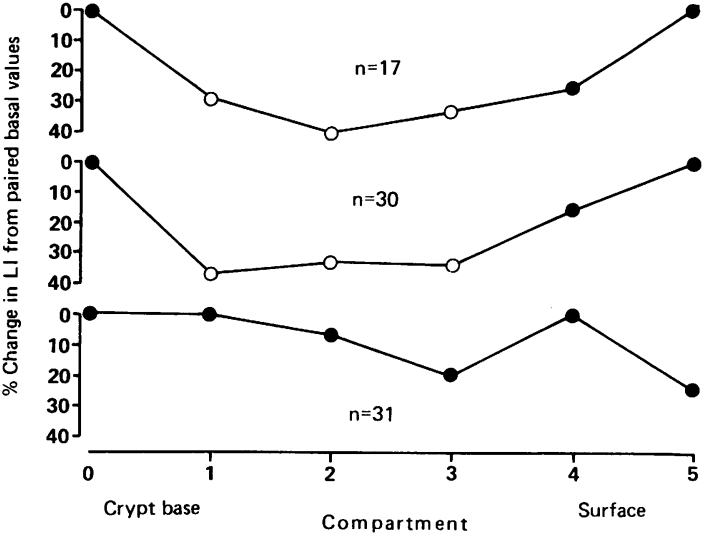

Fig. 3 A significant $(\diamond)(p<0.001)$ fall in LI at four to six weeks (upper panel), eight to 10 weeks (mid panel) of calcium treatment (comparing each with their own basal values), in the basal three-fifths of the crypts and their insignificant fluctuations six to eight weeks (lower panel) after cessation of treatment.

shown in Figure 2, there was significant $(p<0.001)$ and persistent suppression of thymidine uptake as soon as four to six weeks after calcium treatment and this persisted whilst taking calcium. Figure 3 illustrates similar findings in the crypt compartments.

\section{Discussion}

Our results confirm and expand the germinal study published by Lipkin and Newmark. ${ }^{2}$ In a larger cohort, we showed a significant response to the administration of calcium by mouth. The suppression of proliferation occurred within one month and was maintained during therapy as shown by the LI measurement after two months of treatment and, on its cessation, there was a reversal to almost basal values of $L I$.

Whereas Lipkin and Newmark deliberately chose subjects having an abnormally raised LI, our study subjects were chosen from groups believed to be at potentially high risk for colorectal neoplasia and not because of their LI values. Even so, as a group, there was a significant suppression of LI while taking calcium supplementation as compared with both baseline and after treatment levels. Individually, those with an elevated LI responded to calcium, while persons with a basal LI value below the mean baseline value showed no significant upward fluctuation during therapy. Thus, this is a true finding and not a 'regression to the mean' of initially abnormal results. ${ }^{16}$ It appears that calcium supplementation can reduce initially high LI levels, but that it does not affect persons with low baseline LI values. These 
results are consistent with the findings from Lipkin and Newmark's 's trial which was conducted solely on persons with raised LI scores. However, it should be noted that in their work, the study subjects had an initial mean LI of 0.167 whereas in our study the baseline mean LI index was only 0.053 , suggesting that calcium is still effective at considerably lower LI levels. In vitro studies of colonic cell cultures with supplemented calcium also report that not all highrisk persons respond to calcium but mainly those having an abnormally raised $\mathrm{LI} .^{17}$

The time of onset of response, within one month, would indicate that we may be able to shorten our observation period in future intervention studies. The turnover time of colonic epithelial cells is only a few days and it has been shown that within one week the epithelia can change its proliferation pattern after acutely altering subject's diets. ${ }^{18}$ As regards to the duration of effect, we also found that the after-effect of calcium supplementation is short term and that by six to eight weeks after discontinuing treatment, the $\mathrm{Li}$ had almost reverted to basal levels.

Subjects responding to calcium therapy also had a significantly increased number of cells wihin their crypts, while there was a significant suppression of proliferation in the basal three-fifths of the crypt which is the normal site for active proliferation, indicating that morphologically the crypts became more like the quiescent elongated crypts found in vegetarians. ${ }^{19}$ It could be speculated that the turnover time of the crypt cells is lengthened in these persons but proof for this would require further study.

The dosage of calcium used is approximately one and a half times that of the recommended daily dose (RDA) ${ }^{4}$ There is, however, some controversy as to what the RDA should be, in light of our changing Western dietary habits. 21121 The main sources of dietary calcium are dairy products which have not been popular in recent years because of their sometimes high fat content. In addition, the fashion of eating high fibre diets results in an interference with calcium bioavailability and absorption. ${ }^{42}$ Possibly, corrections will have to be made to the RDA according to the dietary habits of the individual. Because it was believed that calcium lactate is a better absorbed calcium preparation we tested two different calcium salts and found no difference in response to these preparations. A recent study ${ }^{21}$ and personal communications from the Sandoz Pharmaceutical Company in Basel and Newmark (USA) have confirmed these impressions.

The mode of effect of calcium on mucosal proliferation has certainly not, as yet, been firmly established. As pointed out by Newmark et $a l^{+}$and shown by experimental studies in animals"2 and in man by Buset et $a l^{2.3}$ using colonic mucosa tissue cultures, the calcium salts have a neutralising effect on potentially noxious agents such as fatty and bile acids. In addition, the latter investigators believe there is a direct beneficial effect of the calcium on the colonic mucosa. If these theories are correct, then the non-absorbed ingested calcium or endogenous intraluminal calcium would be the active principal in suppressing proliferation. It remains to be seen whether the systemic effects of calcium and, or, vitamin $D$ also play a role in inhibiting or potentiating large bowel mucosal proliferation. ${ }^{13}$

As pointed out ${ }^{13}$ from experimental and human studies, raised mucosal proliferation rates are associated with carcinogenesis - while the opposite, suppression of proliferation, has not been proven to prevent the onset of malignancy. This would require longterm observations. The role of calcium in preventing colorectal cancer is certainly not established in spite of the above mentioned epidemiological studies. $^{8 y}$ An analysis by Adler and McKeownEyssen $^{2+}$ of worldwide and national food habits, could not show a clear negative correlation between calcium ingestion and colon cancer rates other than in Finland and Iceland which, interestingly, have a very high consumption of milk products.

In conclusion, we have shown that the LI measure of rectal epithelial proliferation can act as a marker of changes in diet and that calcium significantly suppresses raised proliferation. If these findings are confirmed over a longer observation period, then they may be of use for future intervention studies. Then, only longterm, randomised, clinical trials will be able to clearly show the role, whether crucial or minor, of dietary calcium in the fat-fibre-calorie theory of colon carcinogenesis.

Supported in part by the Sandoz Pharmaceutical Company, Basel. Our thanks to Mrs M. Bleiberg for the laboratory work, to Mrs Y Knaani and Nurse S Falke for coordinating the study and to Mrs A Chetrit for the computer programing. Also to Drs M Lipkin, New York and R Bruce, Toronto, for their constructive suggestions and manuscript review. Presented in part at Digestive Disease Week, Chicago 1987, and published in an abstract form (Gastroenterology 1987; 92: 1603).

\section{References}

1 Ron E, Lubin F. Epidemiology of colorectal cancer and its relevance to screening. In: Rozen $P$. Winawer SJ, eds. Secondary prevention of colorectal cancer. Basel: Karger, 1986: 1-34.

2 Rozen P. Fireman Z. Figer A, Legum C, Ron E, Lynch HT. Family history of colorectal cancer as a marker of potential malignancy within a screening program. Cancer 1987: 60: 248-54. 
3 Rozen P, Horwitz C, Tabenkin C, Ron E, Katz L. Dietary habits and colorectal cancer incidence in a second defined Kibbutz population. Nutr Cancer 1987; 9: $177-84$

4 Newmark HL, Wargowich MJ, Bruce WR. Colon cancer and dictary fat, phosphate and calcium. A hypothesis. JNCI 1984; 72: 1323-5.

5 Wargovich MJ, Eng VWS, Newmark HL, Bruce WR. Calcium ameliorates the toxic effect of deoxycholic acid on colonic epithelium. Carcinogenesis 1983; 9: 1205-7.

6 Wargovich MJ, Eng VWS, Newmark HL. Calcium inhibits the damaging and compensatory proliferative effects of fatty acids on mouse colon epithelium. Cancer 1984; 23: 253-8.

7 Rafter JJ, Eng VWS, Furrer R, Medline A, Bruce WR. The effects of calcium and $\mathrm{pH}$ on the mucosal damage produced by deoxcholic acid in the rat colon. Gut 1986; 27: 1320-9.

8 Garland CF, Garland FC. Do sunlight and vitamin D reduce the likelihood of colon cancer? Int $J$ Epidemiol 1980; 9: 227-31.

9 Garland C, Barrett-Connor E, Rossof AH, Shekelle RB, Criqui MH, Paul O. Dietary vitamin D and calcium and risk of colorectal cancer: A 19-year prospective study in men. Lancet 1985; i: 307-9.

10 Bleiberg H, Buyse M, Galand P. Cell kinetic indicators of premalignant stages of colorectal cancer. Cancer 1985; 56: 124-9.

11 Lipkin M, Blattner WA, Gardner EJ, et al. Classification and risk assessment of individuals with familial polyposis, Gardner's syndrome, and familial nonpolyposis colon cancer from ${ }^{3|\mathrm{H}|}$ thymidine labeling patterns in colonic epithelial cells. Cancer Res 1984; 44: 4201-7.

12 Lipkin M, Newmark $\mathrm{H}$. Effect of added dietary calcium on colonic epithelial-cell proliferation in subjects at high risk for familial colonic cancer. N Engl J Med 1985; 313: $1381-4$.
13 Bresalier RS, Kim YS. Diet and colon cancer. Putting the puzzle together [Editorial]. N Engl J Med 1985: 313: 1413-4.

14 Rozen P. Fireman Z, Baratz M, et al. Screening for colorectal tumors: A progress report of the Tel-Aviv program. In: Rozen P, Winawer SJ, eds. Secondary prevention of colorectal cancer. Bascl: Karger, 1986: 164-81.

15 Deschner EE, Halak A. Rozen P. Gilat T. Prolonged administration of bile salts for gallstone dissolution and its effect on rectal epithelial cell proliferation. Dig Dis Sci 1987; 32: 991-6.

16 Berry DA. Eaton ML. Assessing differential drug effect. Biometrics 1984; 40: 1109-15.

17 Buset M, Lipkin M, Winawer S, Swaroop S, Friedman E. Inhibition of colonic epithelial cell proliferation in vivo and in vitro by calcium. Cancer Res 1986: 46: 5426-30.

18 Stadler J. Stern HS, Yeung KS, et al. Effect of high fat consumption on cell proliferation activity of colorectal mucosa and on soluble fecal bile acids. Gut. (In press).

19 Lipkin M, Uehara K. Winawer S, et al. Seventh-Day Adventist vegetarians have quiescent proliferative activity in colonic mucosa. Cancer Lett 1985; 26: 139-44.

20 Allen LH. Calcium bioavailability and absorption: A review. Am J Clin Nutr 1982; 35: 783-808.

21 Sheikh MS, Santa Ana CA, Nicar MJ, Schiller LR, Fordtram JS. Gastrointestinal absorption of calcium from milk and calcium salts. $N$ Engl J Med 1987; 317: $532-6$.

22 Appleton GVN, Davies PW, Bristol JB, Williamson RCN. Inhibition of intestinal carcinogenesis by dietary supplementation with calcium. Br J Surg 1987; 74: 523-5.

23 Buset M, Lipkin M. Winawer S, Friedman E. Direct and indirect protection of human colonic epithelial cells by calcium [Abstract]. Gastroenterology 1987; 92: 1334.

24 Alder RJ, McKeown-Eyssen G. Calcium intake and risk of colorectal cancer. In: Horwitz C, Rozen P, eds. Progress in diet and nutrition. Basel: Karger, 1988: 177-87. 